Lidy M.J. Pelsser

Klaas Frankena

Jan Toorman

Huub F.J. Savelkoul

Rob Rodrigues Pereira

Jan K. Buitelaar

\title{
A randomised controlled trial into the effects of food on ADHD
}

Abstract The aim of this study

Accepted: 13 March 2008

Published online: 21 April 2008

L.M.J. Pelsser, MSc ( $\square)$

ADHD Research Centre

Liviuslaan 49

5624 JE Eindhoven, The Netherlands

Tel.: +31-40/248-8393

E-Mail: lmjpelsser@worldmail.nl

K. Frankena, MSc, PhD

Quantitative Veterinary Epidemiology

Group

Wageningen University and Research

Centre

Wageningen, The Netherlands

J. Toorman, MD

Department of Pediatrics

Catharina Hospital

Eindhoven, The Netherlands

H.F.J. Savelkoul, $\mathrm{PhD}$

Cell Biology and Immunology Group Wageningen University and Research Centre

Wageningen, The Netherlands

R.R. Pereira, MD

Department of Pediatrics

Medical Centre Rijnmond South

Rotterdam, The Netherlands

J.K. Buitelaar, MD, PhD

Department of Psychiatry

Radboud University Nijmegen Medical

Centre and Karakter, Child and Adolescent

Psychiatry University Centre Nijmegen

Nijmegen, The Netherlands is to assess the efficacy of a restricted elimination diet in reducing symptoms in an unselected group of children with Attention deficit/hyperactivity disorder (ADHD). Dietary studies have already shown evidence of efficacy in selected subgroups. Twenty-seven children (mean age 6.2) who all met the DSM-IV criteria for ADHD, were assigned randomly to either an intervention group (15/27) or a waiting-list control group (12/27). Primary endpoint was the clinical response, i.e. a decrease in the symptom scores by $50 \%$ or more, at week 9 based on parent and teacher ratings on the abbreviated ten-item Conners Scale and the ADHDDSM-IV Rating Scale. The intention-to-treat analysis showed that the number of clinical responders in the intervention group was significantly larger than that in the control group [parent ratings 11/ $15(73 \%)$ versus $0 / 12(0 \%)$; teacher ratings, $7 / 10(70 \%)$ versus $0 / 7$ (0\%)]. The Number of ADHD criteria on the ADHD Rating Scale showed an effect size of 2.1

(cohen's $d$ ) and a scale reduction of $69.4 \%$. Comorbid symptoms of oppositional defiant disorder also showed a significantly greater decrease in the intervention group than it did in the control group (cohens's $d 1.1$, scale reduction 45.3\%). A strictly supervised elimination diet may be a valuable instrument in testing young children with ADHD on whether dietary factors may contribute to the manifestation of the disorder and may have a beneficial effect on the children's behaviour.

Key words ADHD few foods diet - elimination diet - children - randomised controlled trial 


\section{Introduction}

Attention deficit/hyperactivity disorder (ADHD) is one of the most common behavioural disorders in childhood, with symptoms often persisting across adolescence into adulthood [16]. Long-term risk outcomes of children with ADHD include underachievement at school and antisocial personality disorder, delinquency and substance abuse, marital breakdown and unemployment at adult life [19].

ADHD is a multifactorial disorder in which genetic risk factors predominate and various other environmental factors may be involved [5, 32]. The exact aetiological pathways of $\mathrm{ADHD}$, however, are still unknown [22, 31].

According to current professional guidelines, medication and psychosocial interventions are the methods of treatment mostly recommended and most frequently used [12, 18, 31]. According an expert opinion, it is important to avoid overreliance on currently available pharmacological approaches, suggesting that, among others, more research on dietary effects is essential [29]. There is evidence for the effectiveness of an individually constructed elimination diet, the "few foods" approach [15]. Dietary studies using a few foods diet, i.e. a restricted elimination diet consisting of a limited number of foods [7, $8,14,17,25,26]$, have shown evidence of efficacy in subgroups selected for history of food sensitivity or atopic constitution [2]. A Dutch open pilot study in which 40 children with ADHD followed a few foods diet [23], resulted in a reduction of at least $50 \%$ in the symptom scores on rating scales completed by parents and teachers in $62 \%$ of the subjects. The present randomised controlled trial study was designed to assess the efficacy of a few foods diet in a group of ADHD children unselected for affinity with dietary interventions or the presence of physical problems. This study has been registered as an International Standard Randomised Controlled Trial, number ISRCTN47247160.

\section{Methods}

\section{Study population}

Participants were selected from a consecutive series of 79 Dutch children who were referred to the ADHD Research Centre between January and June 2006. Of these children, 27 were enrolled in the trial (Fig. 1). They were between 3.8 and 8.5 years old and they all met the criteria as defined in the Diagnostic and Statistical Manual of Mental Disorders, Fourth Edition (DSM-IV) for ADHD Combined Type or Predominantly Hyperactive-Impulsive Type [1]. The following

Fig. 1 Trial profile

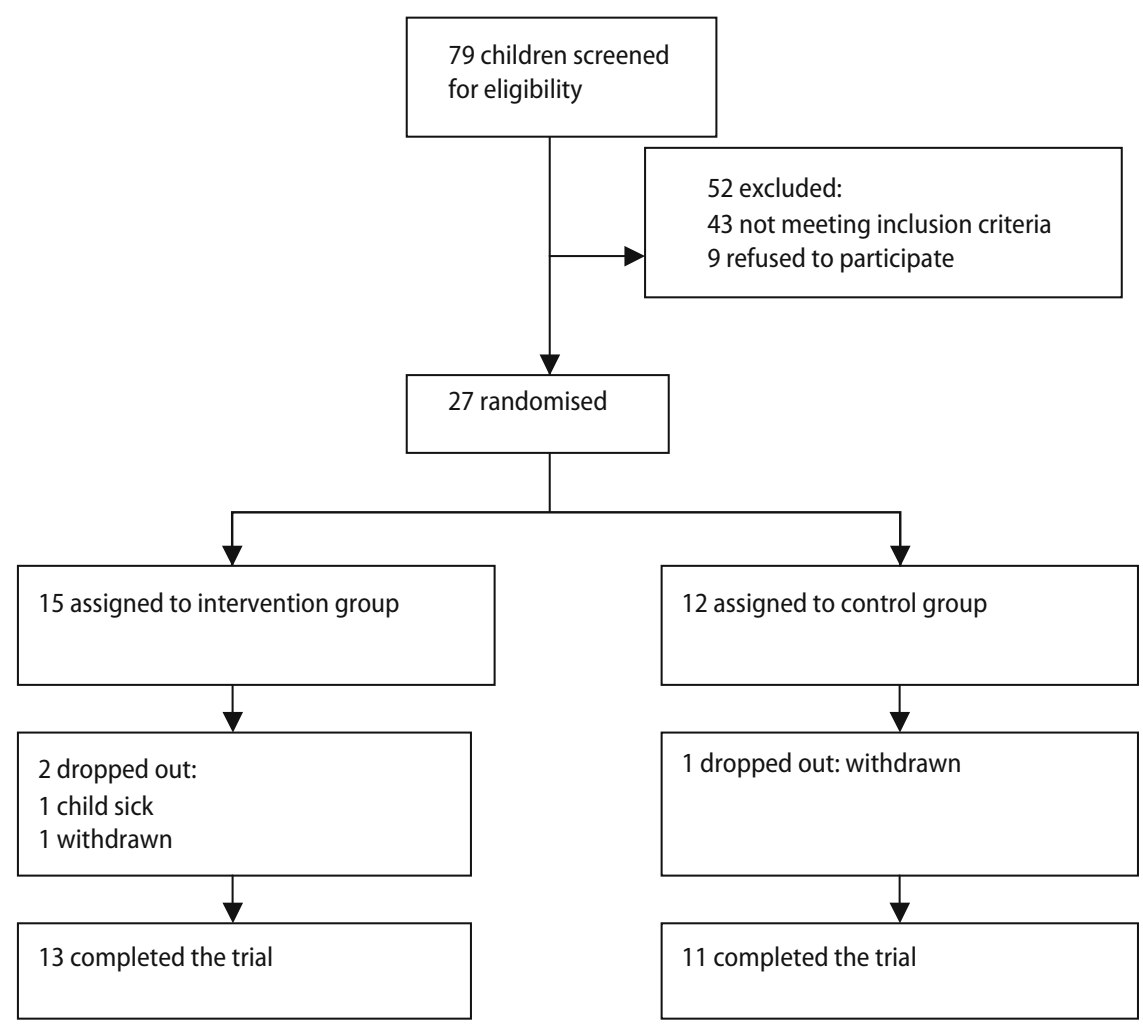


exclusion criteria were used: adopted or foster children, co-existing neurological diseases, an IQ below 70 , prematurity or dysmaturity, use of alcohol, or smoking by mother during pregnancy [31], and co-existence of other psychiatric disorders, except for oppositional defiant disorder (ODD) and conduct disorder (CD). The screening involved a systematic and complete review of the symptoms and diagnostic criteria of all DSM-IV axis I disorders occurring in childhood. None of the children used psychotropic medication.

Parents were given verbal and written information about the study, and duly signed informed parental consent forms were obtained before randomisation. Children who were already on a diet had to cease this diet at least 2 weeks before the start of the trial.

\section{Design and procedures}

The efficacy of an elimination diet in children with ADHD was tested by comparing outcomes in the children randomly assigned to the intervention group to the outcomes in those assigned to the waiting-list (control) group. Subjects were randomly allocated to one of the two groups by means of a sequence of numbered cards in sealed unmarked envelopes that were prepared by an independent paediatrician. Each card contained a reference to the group to which the child would be allocated, and for each allocation an equal number of cards [21] was used. The envelopes were picked and opened by the parents in the presence of the researcher, and treatment was then dispensed in accordance to the allocation on the card.

There were three measurement points: at study entrance (week 0), after the baseline diet (week 3) and after the elimination diet or waiting period (week 9). An overview of the time schedule regarding measure points and rating scales is presented in Table 1.

After the first assessments all children started with a 2-week baseline diet in which they adhered to their normal diet, no foods were eliminated. During the baseline diet the parents kept an extended diary in order to enable an assessment of the child's normal diet, its behaviour and activities. After the baseline diet and the second assessment, the intervention group started with an individually composed elimination diet [15], which had to be followed for a period of 5 weeks. The elimination diet consisted of rice, turkey, lamb, vegetables, fruits, margarine, vegetable oil, tea, pear juice and water $[8,23]$. The control group was placed on a waiting list and continued their own, freely chosen diet. At the start of the trial the parents of the control group were informed that they could start with the elimination diet immediately after the last assessment if they so wished.

Primary endpoints were the parent and teacher ratings on the Abbreviated ten-item Conners Scale (ACS) and the ADHD Rating Scale (ARS) before and after the elimination diet or the waiting period. The ACS [9], has often been used in ADHD treatment studies $[7,8,14,23,25]$. It consists of ten items of behaviour, focusing on overactivity, impulsivity and inattention, and uses a four-point rating scale $(0$ never, 1 sometimes, 2 often, 3 always). The ARS is a frequently used rating scale based on the DSM-IV criteria for ADHD [21,29]. The scores are divided in three parts: the Number of ADHD criteria (18 in all), the nine items regarding inattention and the nine items regarding impulsivity and hyperactivity, the latter both marked out on a four-point rating scale [13].

Secondary endpoints were parent ratings on ODD symptoms measured by a structured psychiatric interview (SPI) based on the DSM-IV-criteria for ODD.

The parents and teachers who filled in the questionnaires could not be blinded as they had to supervise the food intake of the child and knew whether the child was following an elimination diet.

\section{Statistical analysis}

SPSS version 9.0 was used for all statistical analyses. Data was analysed on an intention-to-treat basis, with

Table 1 Time table

\begin{tabular}{llllll}
\hline & Measure points & Rating scales parents & Rating scales teacher & Intervention group & Control group \\
\hline Week 1 & 1 & ACS-1, ARS-1 & & Start of baseline diet & Start of baseline diet \\
Week 2 & Entrance trial & & & Baseline diet & Baseline diet \\
Week 3 & 2 & ACS-2, ARS-2 & ACS-2 & Baseline diet ends & Baseline diet ends \\
Week 4-9 & After baseline & SPI & ARS-2 & Elimination diet starts & $\begin{array}{l}\text { Waiting list starts } \\
\text { Waiting list }\end{array}$ \\
Week 9 & 3 & ACS-3, ARS-3 & ACS-3 & Elimination diet & Waiting list ends \\
& At endpoint & SPI & ARS-3 & & Elimimination diet starts (if desired) \\
\hline
\end{tabular}

ACS abbreviated conners scale, ARS ADHD rating scale, SPI structured psychiatric interview 
last observations carried forward in cases of missing data. Descriptive parameters for indicating effect size were $\%$ scale reduction and Cohen's $d$. Effects were tested at $P<0.05$; all testing was two-tailed. Subjects were defined as showing clinically significant improvement (responders) if the difference between measure point 3 (after the elimination diet) and measure point 2 (after the baseline diet) was $50 \%$ or more on both the ACS and the ARS. Data was analysed by Student's $t$ test and Fisher's exact test.

\section{Results}

In sum 79 children were screened for eligibility, 43 of these failed to meet the inclusion criteria, and 9 refused to participate. As a result 27 children entered the study and were randomised to the intervention group [15] or the control group [12]. The descriptive characteristics of the subjects enrolled are presented in Table 2. Of the 27 children, $3(11 \%)$ were lost to follow up: one child assigned to the control group withdrew after randomisation, whilst two children assigned to the intervention group dropped out, one because of illness, the other because the parents lacked motivation to stick to the diet (see Fig. 1). For 17 of the 27 children, teacher data was available, in the other cases school contact at both Baseline and Endpoint rating was not possible due to holidays or teacher's illness.

\section{Primary outcomes}

Table 3 shows the parent ratings on the ACS, ARS and the SPI for both the intervention group and the control group (1) at the start of the trial, (2) after the baseline diet, and (3) at the end of the trial. The mean scores at the start of the trial and after the baseline diet was greater than 22.7 points (ACS) and 13.7 points (ARS Number of ADHD criteria, 18 at the most) in both the intervention and the control groups. There was no significant difference in the scores of both measurement points. At the end of the trial the mean scores in the intervention

Table 2 Descriptive characteristics of study participants at time of inclusion

\begin{tabular}{lcc}
\hline & $\begin{array}{c}\text { Intervention } \\
\text { group N (\%) }\end{array}$ & $\begin{array}{l}\text { Control } \\
\text { group N (\%) }\end{array}$ \\
\hline Number of participants & 15 & 12 \\
Boys & $12 / 15(80.0 \%)$ & $10 / 12(83.3 \%)$ \\
Age (mean (SD)) & $6.3(1.6)$ & $6.1(1.7)$ \\
ADHD combined type & $10 / 15(66.7 \%)$ & $8 / 12(66.7 \%)$ \\
ADHD predominantly & $5 / 15(33.3 \%)$ & $4 / 12(33.3 \%)$ \\
hyperactive-impulsive type & & \\
Co-morbid ODD & $12 / 15(80.0 \%)$ & $10 / 12(83.3 \%)$ \\
On dietary restriction & $0 / 15(0 \%)$ & $1 / 12(8.3 \%)$ \\
\hline
\end{tabular}

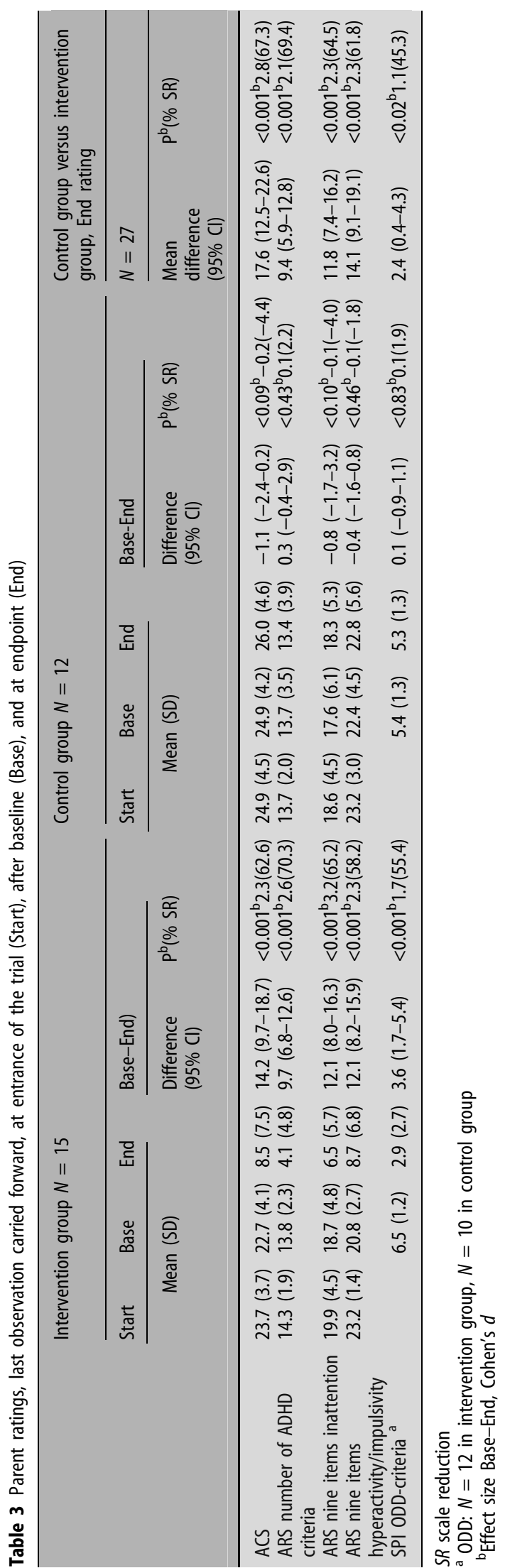


group showed a $62.6 \%$ improvement on the ACS and a $70.3 \%$ improvement on the ARS Number of ADHD criteria $(P<0.001)$. In the waiting-list group the scores increased by $4.4 \%$ (ACS) and decreased by $2.2 \%$ (ARS Number of ADHD criteria). Children in the intervention group showed a significantly greater decrease in behaviour problems than children in the control group, with a treatment effect-i.e. the difference in improvement between the intervention and control group-of 17.6 (95\% Confidence Interval (CI) 12.5-22.6, $P<0.001$, Student's $t$ test) on the ACS and 9.4 (95\% CI 5.9-12.8, $P<0.001)$ on the ARS Number of ADHD criteria. The treatment effect on the ARS included both inattention symptoms (mean difference 11.8, $P<0.001$ ) and hyperactivity/impulsivity symptoms (mean difference 14.1, $P<0.001$ ). The effect size (Cohen's $d$ ) was 2.8 (67.3\% scale reduction) on the ACS and 2.1 (69.4\% scale reduction) on the ARS Number of ADHD criteria. According to the parent ratings $11 / 13$ children (85\%) in the intervention group who completed the study showed an improvement of $50 \%$ or more, (mean difference on the Number of ADHD criteria 11.2 (95\% CI 9.0-13.5, $P<0.001)$. None of the children in the control group $(0 / 11)$ showed an improvement of $50 \%$ or more (mean difference on the Number of ADHD criteria 0.3 (95\% CI -0.4 to $0.9, P<0.43$ ).

Table 4 shows the teacher ratings on the ACS and the ARS for both the intervention group and the control group (1) after the baseline diet, and (2) at the end of the trial. The parents' conclusions in Table 3 were confirmed by the teachers. The treatment effect was 13.3 on the ACS (95\% CI 7.5-19.1, $P<0.001)$ and 8.4 on the ARS Number of ADHD criteria (95\% CI 4.8-11.9, $P<0.001$ ), including both inattention symptoms (mean difference $8.3, P<0.011$ ) and hyperactivity/impulsivity symptoms (mean difference $12.8, P<0.002$ ). The effect size (Cohen's $d$ ) was 2.4 (64.3\% scale reduction) on the ACS and 2.5 (70.6\% scale reduction) on the ARS Number of ADHD criteria.

According to the parent ratings, 11 out of the 15 children in the intervention group (73\%) could be classified as responders, defined as showing behavioural improvement of at least $50 \%$ on both the ACS and the ARS. All responders did not meet the DSM-IV-criteria for ADHD anymore. In the control group, none of the 12 children $(0 \%)$ were classified as responders (two-tailed Fisher's exact test, $P<0.001)$. According to the teacher ratings $(N=17) 7 / 10$ children in the intervention group were responders $(70 \%)$, versus $0 / 7$ children $(0 \%)$ in the control group (two-tailed Fisher's exact test, $P<0.01$ )

\section{Secondary outcomes}

At the entrance of the trial, $12 / 15$ children in the intervention group (80\%) and $10 / 12$ children in the

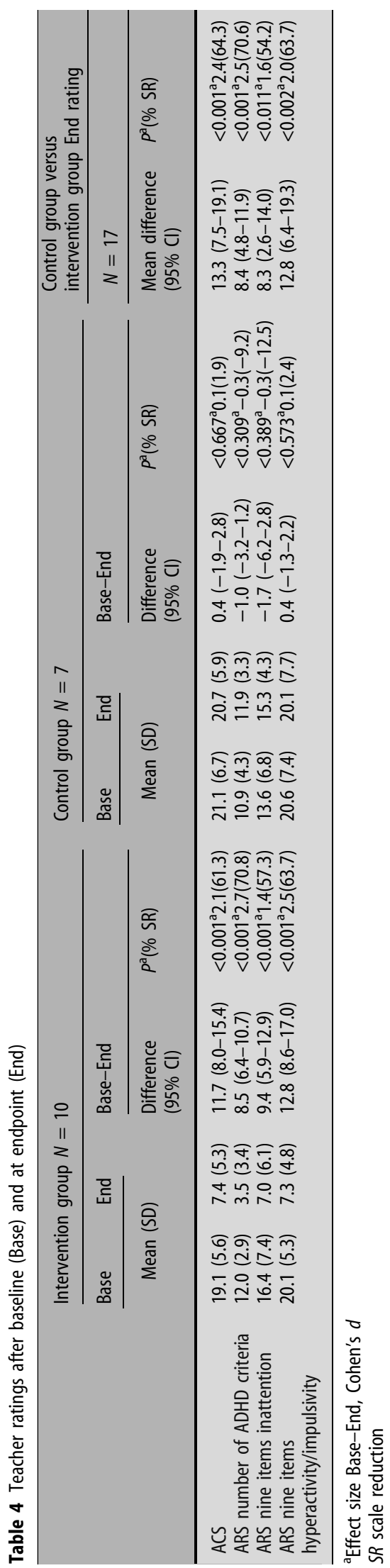


control group (83\%) met the DSM-IV-criteria for ODD according to the SPI (see Table 3 ). The mean number of ODD-symptoms was 6.5 in the intervention group (the DSM-IV-diagnostic criteria for ODD are met if the child complies with four or more out of eight symptoms) and 5.4 in the control group. At the end of the trial, 4/15 children in the intervention group $(27 \%)$ and $10 / 12$ children in the control group (83\%) still met the ODD-criteria, the mean number of ODD-symptoms now being 2.9 in the intervention group and 5.3 in the control group. The difference between the measure points at the beginning and at the end of the trial was 3.6 (95\% CI 1.7-5.4, $P<0.001$ ) in the intervention group and $0.1(95 \% \mathrm{CI}-0.9$ to 1.1 , $P<0.83$ ) in the control group, with a mean difference of 2.4 (95\% CI $0.4-4.3, P<0.02)$. The effect size (Cohens's $d$ ) was 1.1 (45.3\% scale reduction).

\section{Discussion}

Our results show that a carefully supervised few foods diet in young children with ADHD, followed for 5 weeks at the most, can exhibit substantial changes in behaviour. Seventy percent of the children showed behavioural improvements of $50 \%$ or more according to the ratings of parents and teachers and did not meet the DSM-IV-criteria for ADHD anymore. The results of this randomised controlled study do not differ from the results of equivalent studies $[7,8,14,17,25,26]$. All controlled trials on ADHD and foods using a few foods diet show a more or less beneficial effect on the behaviour of the subjects. The extent of restriction of the elimination diet seems important and may affect the degree of the behavioural improvements: a diet including too many foods may reduce the number of responders [25]. Consequently, a diet excluding just one or a limited number of foods, like sugar or additives, would be of little benefit to children with ADHD [8, 10, 15]. Recent additive trials have shown that some degree of hyperactivity, when exposed to artificial food colours and benzoate preservatives, may be applied to all 3-yearold children, not exclusively to hyperactive children [4, 20]. This might imply that there is a general adverse effect of additives or preservatives on the behaviour of all young children, with a small effect size (0.18).

As we wanted to investigate the influence of foods on ADHD, we excluded children with potentially predisposing environmental risk factors for ADHD, like prematurity, dysmaturity and foetal exposure to maternal alcohol or cigarettes [31]. Efforts were made to obtain an unbiased sample, the children were not preselected for affinity with dietary intervention.

At the entrance of the study, 22/27 children also met the criteria for ODD, $80 \%$ of the children in the intervention group and $83 \%$ of the children in the control group. Co-existence of ODD is very common in ADHD [31]. At the end of the trial, all children in the control group still met the criteria, but in the intervention group the number of children meeting the ODD-criteria had diminished by $66 \%$. We expected the children in the intervention group to show deterioration of their ODD behaviour, opposing the dietary restrictions which they surely would not like.

It appears as if the elimination diet triggers a significant change in both ADHD-symptoms and ODDsymptoms. This is important, as ADHD-children with co-morbid ODD/CD are at risk for long-term maladjustment [3]. It is tempting to speculate that the appliance of an elimination diet in young children might reduce this risk.

\section{Study limitations}

This study is an open-label controlled trial, without placebo. The elimination diet used in this study was very restricted, only a few foods were allowed, thus making it impossible to compose a reliable placebo diet. The fact that even a small change in the diet of a child, like removing additives, may have a beneficial effect on the behaviour of children [4,20], illustrates the difficulties of constructing a placebo diet. Parents and teachers were aware of the intervention, which is a limitation that needs to be acknowledged. Although open randomised controlled trials are commonly used when blinding is difficult $[6,11,24,27,28,30,33,34]$, we recommend replication of this trial with blinded measurements by an independent observer [6]. Also the incorporation in future studies of objective tests of attentional performance and executive functioning should be considered.

It is conceivable that the increased attention for the child during the elimination diet contributes to the behavioural improvements. In order to measure the effects of increased attention during this trial, all parents had to keep an extended diary during the baseline diet, having to watch their child carefully. The second assessment took place at the end of the baseline diet. There were no significant differences between the scores at the entrance of the trial and after baseline. Still the placebo effects of expectation and intense caregiver involvement have to be considered.

The adherence to a restricted elimination diet can be considered as burdensome, dietary management is difficult and puts a considerable strain on the family [8], so this method will not be applicable to all children with ADHD. Still dietary investigation can be an option for some children, and parents who are interested should be offered the possibility to follow a few foods diet with their child, provided that a trained 
dietician is available to supervise the intervention [15]. If the diet has a beneficial effect on the behaviour, challenge tests with specific foods should be exhibited to identify the incriminated foods and to make the diet more manageable. Further research could focus on the follow up of dietary interventions in children with ADHD and on the feasibility of longterm dietary restrictions.

The mechanisms in which foods exerts its effects remain unclear. Toxic, pharmacological, or immunologic mechanisms could be involved and the physiological effects of different foods may vary [8]. More research on this topic is needed.

In conclusion, this study confirms the results of earlier studies $[7,8,14,17,25,26]$, that a strictly supervised and restricted elimination diet can affect the behaviour of some children with ADHD and may be a valuable instrument in testing young children with ADHD on whether dietary factors may contribute to the manifestation of the disorder.

Acknowledgments We acknowledge the support for this study by the Foundation for Children's Welfare Stamps Netherlands; Foundation Nuts Ohra; Matty Brand Foundation; and the Foundation of Child and Behaviour. The funding sources had no role in the study design, data collection, analysis or interpretation of the data, had no input into the writing of the report, or in the decision to submit for publication.

Conflict of interest We declare that we have no conflict of interest.

\section{References}

1. American Psychiatric Association (1994) Diagnostic and statistical manual of mental disorders, 4th edn. APA, Washington

2. Arnold LE (1999) Treatment alternatives for ADHD. J Atten Disord 3:30-48

3. Barkley RA (1998) Attention-deficit hyperactivity disorder: a handbook for diagnosis and treatment. Guilford Press, New York

4. Bateman B, Warner JO, Hutchinson E, Dean T, Rowlandson P, Gant C, Grundy J, Fitzgerald C, Stevenson J (2004) The effects of a double blind, placebo controlled, artificial food colourings and benzoate preservative challenge on hyperactivity in a general population sample of preschool children. Arch Dis Child 89:506-511

5. Biederman J, Faraone SV (2005) Attention-deficit hyperactivity disorder. Lancet 366:237-248

6. Bockting CL, Schene AH, Spinhoven P, Koeter MW, Wouters LF, Huyser J, Kamphuis JH (2005) Preventing relapse/recurrence in recurrent depression with cognitive therapy: a randomized controlled trial. J Consult Clin Psychol 73:647-657

7. Boris M, Mandel FS (1994) Food and additives are common causes of the attention deficit hyperactive disorder in children. Ann Allergy 72:462-468

8. Carter CM, Urbanowicz M, Hemsley R, Mantilla L, Strobel S, Graham PJ, Taylor E (1993) Effects of a few food diet in attention deficit disorder. Arch Dis Child 69:564-568

9. Conners $\mathrm{CK}$, Goyette $\mathrm{CH}$, Southwick DA, Lees JM, Andrulonis PA (1976) Food additives and hyperkinesis: a controlled double-blind experiment. Pediatrics 58:154-166
10. Cruz NV, Bahna SL (2006) Do food or additives cause behavior disorders? Pediatr Ann 35:744-745, 748-754

11. Deale A, Chalder T, Marks I, Wessely S (1997) Cognitive behavior therapy for chronic fatigue syndrome: a randomized controlled trial. Am J Psychiatry 154:408-414

12. Dulcan M (1997) Practice parameters for the assessment and treatment of children, adolescents, and adults with attention-deficit/hyperactivity disorder. American Academy of Child and Adolescent Psychiatry. J Am Acad Child Adolesc Psychiatry 36:85S-121S

13. Dupaul GR (1991) Parent and teacher ratings of ADHD symptoms: Psychometric properties in a community-based sample. J Clin Child Psychol 20:242-253

14. Egger J, Carter CM, Graham PJ, Gumley D, Soothill JF (1985) Controlled trial of oligo-antigenic treatment in the hyperkinetic syndrome. Lancet 1:540-545

15. Hill P, Taylor E (2001) An auditable protocol for treating attention deficit/ hyperactivity disorder. Arch Dis Child 84:404-409

16. Hill P (2005) Attention deficit/hyperactivity disorder. Arch Dis Child 90:i1

17. Kaplan BJ, McNicol J, Conte RA, Moghadam HK (1989) Dietary replacement in preschool-aged hyperactive boys. Pediatrics 83:7-17

18. Kutcher S, Aman M, Brooks SJ, Buitelaar J, van Daalen E, Fegert J, Findling RL, Fisman S, Greenhill LL, Huss M, Kusumakar V, Pine D, Taylor E, Tyano S (2004) International consensus statement on attention-deficit/ hyperactivity disorder (ADHD) and disruptive behaviour disorders (DBDs): clinical implications and treatment practice suggestions. Eur Neuropsychopharmacol 14:11-28
19. Mannuzza S, Klein RG, Bessler A, Malloy P, LaPadula M (1993) Adult outcome of hyperactive boys. Educational achievement, occupational rank, and psychiatric status. Arch Gen Psychiatry 50:565-576

20. McCann D, Barrett A, Cooper A, Crumpler D, Dalen L, Grimshaw K, Kitchin E, Lok K, Porteous L, Prince E, Sonuga-Barke E, Warner JO, Stevenson $\mathrm{J}$ (2007) Food additives and hyperactive behaviour in 3-year-old and 8/9-yearold children in the community: a randomised, double-blinded, placebocontrolled trial. Lancet 370:1560-1567

21. Michelson D, Faries D, Wernicke J, Kelsey D, Kendrick K, Sallee FR, Spencer T, Atomoxetine ADHD Study Group (2001) Atomoxetine in the treatment of children and adolescents with attention-deficit/hyperactivity disorder: a randomized, placebocontrolled, dose-response study. Pediatrics 108:E83

22. National Institutes of Health Consensus Development Conference Statement: diagnosis and treatment of attention-deficit/hyperactivity disorder (ADHD) (2000) J Am Acad Child Adolesc Psychiatry 39:182-193

23. Pelsser LMJ, Buitelaar JK Gunstige invloed van een standaardeliminatiedieet op het gedrag van jonge kinderen met aandachtstekorthyperactiviteitsstoornis (ADHD), een verkennend onderzoek. Ned Tijdschr Geneeskd 146:2543-2547

24. Prins JB, Bleijenberg G, Bazelmans E, Elving LD, de Boo TM, Severens JL, van der Wilt GJ, Spinhoven P, van der Meer JW (2001) Cognitive behaviour therapy for chronic fatigue syndrome: a multicentre randomised controlled trial. Lancet 357:841-847 
25. Schmidt MH, Mocks P, Lay B, Eisert HG, Fojkar R, Fritz-sigmund D, Marcus A, Musaeus B (1997) Does oligoantigenic diet influence hyperactive/conductdisordered children, a controlled trial. Eur Child Adolesc Psychiatry 6:88-95

26. Schulte-Korne G, Deimel W, Guttenbrunner $\mathrm{C}$, Hennighausen $\mathrm{K}$, Blank R, Rieger C, Remschmidt H (1996) Effect of an oligo-antigen diet on the behavior of hyperkinetic children. Z Kinder Jugendpsychiatr Psychother 24:176183

27. Smithuis F, Kyaw MK, Phe O, Aye KZ, Htet L, Barends M, Lindegardh N, Singtoroj T, Ashley E, Lwin S, Stepniewska K, White NJ (2006) Efficacy and effectiveness of dihydroartemisinin-piperaquine versus artesunate-mefloquine in falciparum malaria: an open-label randomised comparison. Lancet 367:2075-2085
28. Staab D, Diepgen TL, Fartasch M, Kupfer J, Lob-Corzilius T, Ring J, Scheewe S, Scheidt R, Schmid-Ott G, Schnopp C, Szczepanski R, Werfel T, Wittenmeier M, Wahn U, Gieler U (2006) Age related, structured educational programmes for the management of atopic dermatitis in children and adolescents: multicentre, randomised controlled trial. Br Med J 332:933938

29. Steer CR (2005) Managing attention deficit/hyperactivity disorder: unmet needs and future directions. Arch Dis Child 90:19-25

30. Stulemeijer M, de Jong LW, Fiselier TJ, Hoogveld SW, Bleijenberg G (2005) Cognitive behaviour therapy for adolescents with chronic fatigue syndrome: randomised controlled trial. Br Med J 330:14-19
31. Taylor E, Dopfner M, Sergeant J, Asherson P, Banaschewski T, Buitelaar J, Coghill D, Danckaerts M, Rothenberger A, Sonuga-Barke E, Steinhausen HC, Zuddas A (2004) European clinical guidelines for hyperkinetic disorder-first upgrade. Eur Child Adolesc Psychiatry 13:17-30

32. Taylor E, Rogers JW (2005) Practitioner review: early adversity and developmental disorders. J Child Psychol Psychiatry 46:451-467

33. Van Wijck AJ, Opstelten W, Moons KG, van Essen GA, Stolker RJ, Kalkman CJ, Verheij TJ (2006) The PINE study of epidural steroids and local anaesthetics to prevent postherpetic neuralgia: a randomised controlled trial. Lancet 367:219-224

34. Wilson DC, Cairns P, Halliday HL, Reid M, McClure G, Dodge JA (1997) Randomised controlled trial of an aggressive nutritional regimen in sick very low birthweight infants. Arch Dis Child Fetal Neonatal Ed 77:F4-F11 